\title{
Incident solar radiation simulated by general circulation models for the southwestern United States
}

\author{
Anthony J. Brazel ${ }^{1}$, Gregory J. McCabe, $\mathrm{Jr}^{2}$, Herbert J. Verville ${ }^{1}$ \\ ' Office of Climatology, Department of Geography, Arizona State University, Tempe, Arizona 85287-1508, USA \\ ${ }^{2}$ United States Geological Survey, Box 25046 Mail Stop 412, Denver Federal Center, Lakewood, Colorado 80225, USA
}

\begin{abstract}
Estimates of incident solar radiation for the southwestern United States from 4 general circulation models (GCMs) are evaluated by comparison to observed values. Results indicate that GCMs reliably simulate the annual solar cycle, but generally underestimate incident solar radiation for the southwestern United States. For climatic conditions resulting from a doubling of atmospheric carbon dioxide, the 4 GCMs evaluated in this study estimate increases of 1 to $3 \%$ of mean annual incident solar radiation simulated for current climatic conditions.
\end{abstract}

\section{INTRODUCTION}

General circulation models (GCMs) are mathematical representations of the earth-climate system and are used, among other things, to estimate the effects of increasing atmospheric carbon dioxide and other radiative gases ('greenhouse' gases) on global climate. Several GCMs have been developed by various research groups, and are continually being improved and updated, e.g. Geophysical Fluid Dynamics Laboratory (GFDL), Goddard Institute of Space Studies (GISS), National Center for Atmospheric Research (NCAR), Oregon State University (OSU), and the United Kingdom, British Meteorological Office (UKMO). Although GCMs are able to reproduce the general spatial and temporal distributions of most climatic variables on a global scale, GCM estimates of climate on regional scales $\left(10^{4}\right.$ to $\left.10^{6} \mathrm{~km}^{2}\right)$ vary markedly from observations (Grotch \& MacCracken 1991). The coarse grid systems (e.g. $4^{\circ}$ of latitude by $5^{\circ}$ of longitude) used by GCMs to calculate climatic variables are, in part, responsible for the inaccuracy of GCM estimates on regional scales. In an attempt to evaluate the performance of GCMs, several studies have evaluated the reliability of GCM estimates of various climatic variables such as temperature, precipitation, sea-level pressure, and solar radiation for various regions of the world (e.g. Grotch 1988, Mearns et al. 1989, Boer et al. 1991, Kalkstein 1991).
Incoming solar radiation is an important component of the earth's energy balance and has a large effect on the earth-climate system. The U.S. Environmental Protection Agency (U.S. EPA) sponsored a study of GCM estimates of incoming solar radiation (incident solar radiation) for several areas of the United States: the Great Lakes region, the Great Plains, the southeastern United States, and the northwestern United States (Mearns et al. 1989). The southwestern United States was not included in the study, but is the most homogeneous solar region of the United States, as it exhibits the highest degree of spatial covariability of incident solar radiation of any region within the conterminous United States (Willmott \& Vernon 1980). Because of the high degree of spatial covariability of incident solar radiation in this region, and because GCMs operate using coarse grid systems, the southwestern United States offers an opportunity to perform an evaluation of GCM estimates of incident solar radiation resulting from grid systems at a scale appropriate for regional models.

In this paper, a comparison of GCM estimates of incident solar radiation for current climatic conditions $\left(1 \times \mathrm{CO}_{2}\right)$ to observed values is presented for the southwestern United States. In addition, GCM estimates of incident solar radiation for doubled- $\mathrm{CO}_{2}\left(2 \times \mathrm{CO}_{2}\right)$ conditions are examined. 


\section{METHODS}

Grid point estimates of mean monthly values of incident solar radiation ( $\mathrm{W} \mathrm{m} \mathrm{m}^{-2} \mathrm{~d}^{-1}$ ) from the GFDL, GISS, OSU and UKMO GCMs were obtained from NCAR. The GCMs used in this study all differ in their level of physical detail and mathematical complexity, and each operates on a different grid system. The version of the GFDL GCM used in this study uses one of the highest resolution grid systems currently being used by GCMs (approximately $2.25^{\circ}$ of latitude by $3.75^{\circ}$ of longitude) (Manabe \& Broccoli 1990). In contrast, the version of the GISS GCM used in this study uses one of the lowest resolution grid systems $\left(8^{\circ}\right.$ of latitude by $10^{\circ}$ of longitude) (Hansen et al. 1983). The OSU and UKMO GCMs operate using intermediate grid system resolutions of $4^{\circ}$ of latitude by $5^{\circ}$ of longitude, and $5^{\circ}$ of latitude by $7.5^{\circ}$ of longitude, respectively (Schlesinger \& Gates 1980). Differences in the levels of physical detail and mathematical complexity among GCMs cause variations in estimates of incident solar radiation for $1 \times \mathrm{CO}_{2}$ and $2 \times \mathrm{CO}_{2}$ simulations. This study does not address the complex issues of understanding and explaining differences among GCM estimates. The primary focus is the evaluation of how similar GCM estimates of incident solar radiation are to observed values for $1 \times \mathrm{CO}_{2}$ climatic conditions for the southwestern United States.

Observed values of mean monthly incident solar

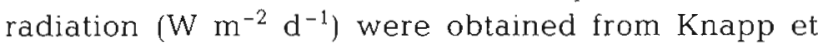
al. (1990) for 46 stations located within the southwestern United States (Fig. 1). Because the location of the solar radiation observation stations and the location of the grid points for each of the $4 \mathrm{GCMs}$

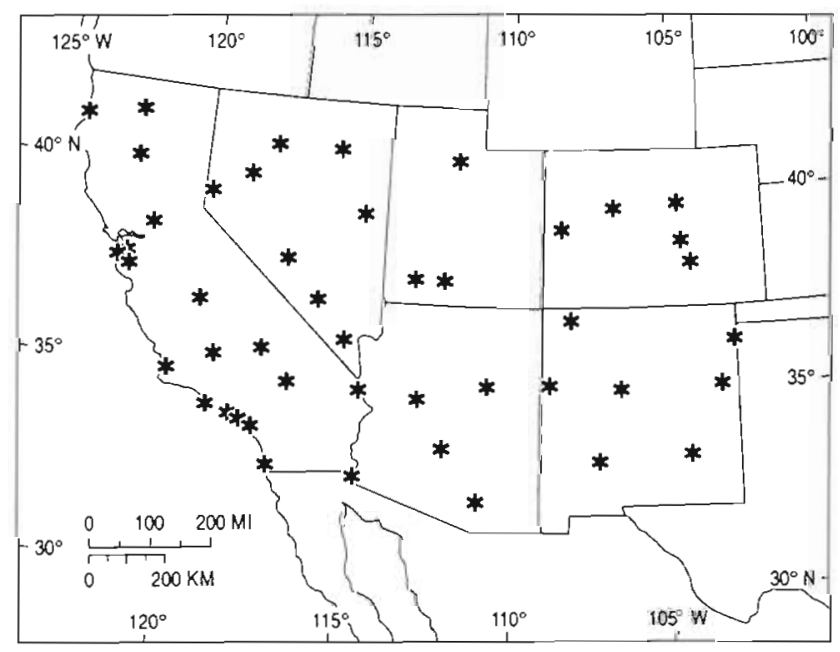

Fig. 1 Solar radiation observation stations used in the study. Data from Knapp et al (1990) used in this study differ, the observed data were interpolated to each of the GCM grid systems to perform more appropriate comparisons between GCM-simulated values and observed values. The interpolation was accomplished through an algorithm based on spherical coordinates that accounts for the curvature of the earth (Willmott et al. 1985). Comparison to the 4 GCM grid systems was performed only within the area bounded by the solar radiation observation stations (Fig. 1). This approach was used to ensure that there were enough observed data points to provide reliable interpolated values for the GCM grid points included in this study. By using this approach, only a limited number of grid points from each GCM could be used ( 17 from the GFDL model, 2 from the GISS model, 8 from the OSU model, and 4 from the UKMO model) (Fig. 2).

Because only a limited number of grid points from each GCM were included in this study, and because of the coherent nature of incident solar radiation in the southwestern United States, comparisons between GCM-simulated values of incident solar radiation and observed values were performed by using mean monthly, mean seasonal, and mean annual values for the entire region. In addition, changes in GCM-simulated values of incident solar radiation from $1 \times \mathrm{CO}_{2}$ to $2 \times \mathrm{CO}_{2}$ conditions were examined.

The primary statistic calculated for the comparisons between the GCM-simulated values of incident solar radiation and observed values is the bias, which is the GCM-simulated value minus the observed value. For comparisons between mean monthly GCMsimulated and observed values, the correlation coefficient $(\mathrm{r})$, the root mean square error (RMSE), and the index of agreement $(d)$ were calculated (Willmott 1981). These statistics are included in Table 1, along with the equations used. The index of agreement is a measure of relative error in model estimates. It is a dimensionless number and ranges from 0.0 to 1.0 , where 0.0 describes complete disagreement between estimated and observed values, and 1.0 indicates that the estimated and observed values are identical. The index of agreement is used because the correlation coefficient ( $r$ ) cannot account for additive differences or differences in proportionality (Willmott 1981). The index of agreement is sensitive to differences between observed and estimated means, as well as to certain changes in proportionality (Willmott 1981). The $r$ (measure of covariability between observed and modeled values) and RMSE (measure of average difference between observed and modeled values) statistics are included because they indicate different components of model error indicated by $d$. 


\section{a. GFDL}

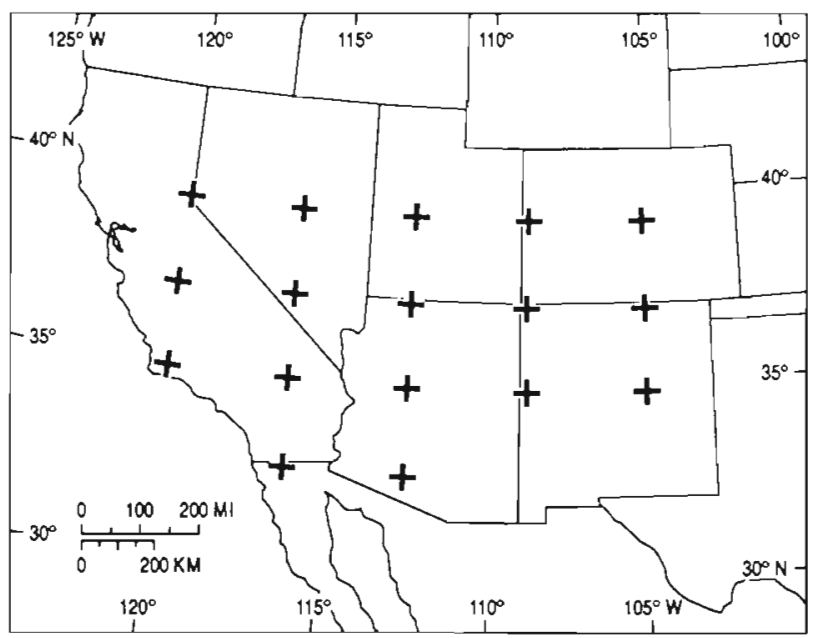

\section{c. OSU}

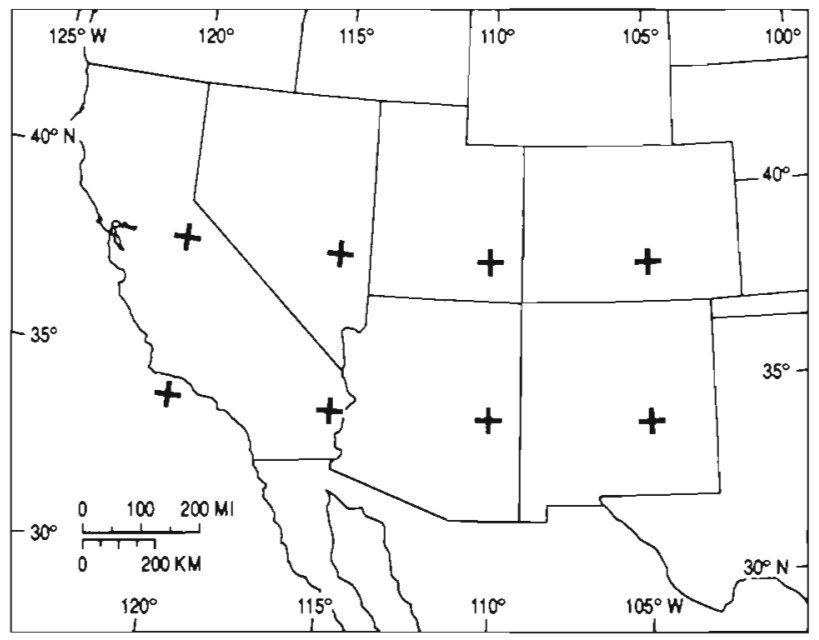

\section{b. GISS}

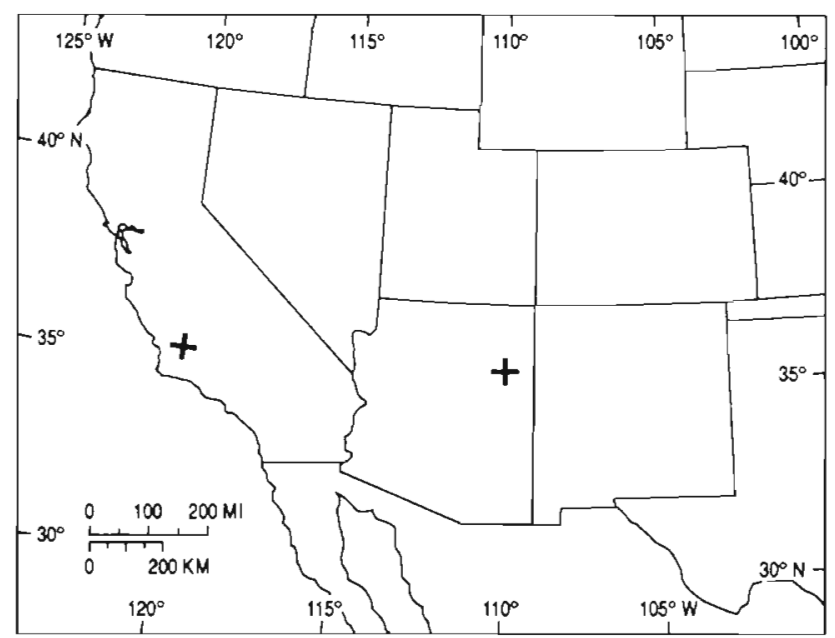

\section{d. UKMO}

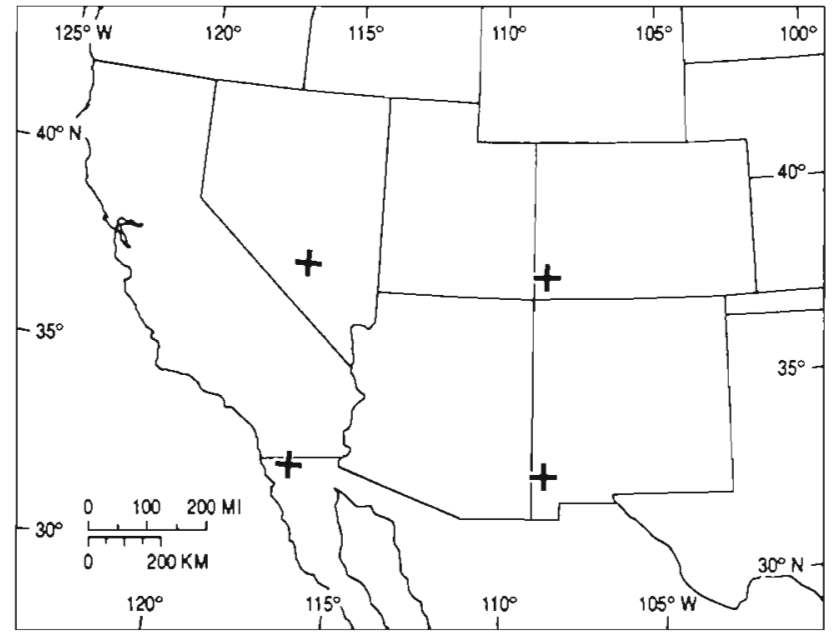

Fig. 2. GCM grid points used in the study from 4 simulations: (a) GFDL, Geophysical Fluid Dynamics Laboratory; (b) GISS, Goddard Institute for Space Studies; (c) OSU, Oregon State University; (d) UKMO, United Kingdom, British Meteorological Office

\section{RESULTS AND DISCUSSION}

Comparison of mean monthly GCM-simulated and observed values of incident solar radiation for the southwestern United States indicates high correlations between GCM-simulated values and observed values that are significant at $\alpha=0.01$; however, except for the GFDL GCM simulations, there are large differences between the magnitudes of GCM-simulated and observed values, as indicated by large values of bias and large RMSEs (Table 1). The high correlations indicate that the GCMs reliably simulate the annual solar cycle, but the large biases and RMSEs for the GISS, OSU, and UKMO simulations indicate that these GCMs do not simulate the magnitude of incident solar radiation well. All of the GCMs analyzed in this study underesti- mate incident solar radiation for the southwestern United States. The comparison of GFDL-simulated values with observed values produced the smallest bias, the smallest RMSE, and the largest correlation and index of agreement of all the GCM comparisons with observed values. The comparison of the GISSsimulated values with observed values produced the lowest correlation, the largest RMSE and the lowest index of agreement of all the GCM comparisons with observed values. The largest bias resulted from the comparison of the OSU simulated values with the observed values.

In a study of GCM-simulated incident solar radiation for the Great Lakes region, the Great Plains, the southeastern United States, and the northwestern United States, Mearns et al. (1989) found that GCMs were 
Table 1. Comparison of observed mean monthly incident solar radiation to estimates from 4 GCMs: Geophysical Fluid Dynamics Laboratory (GFDL), Goddard Institute for Space Studies (GISS), Oregon State University (OSU), and United Kingdom Meteorology Office (UKMO). Bias: GCM-simulated value minus observed value, in $W \mathrm{~m}^{-2} \mathrm{~d}^{-1}$; ; correlation coefficient; RMSE: root mean square error, in $W \mathrm{~m}^{-2} \mathrm{~d}^{-1}$; d: index of agreement

\begin{tabular}{|c|c|c|c|c|}
\hline GCM & Bias & $r^{a}$ & RMSE & $d$ \\
\hline GFDL & -4 & 0.98 & 22 & 0.96 \\
\hline GISS & -18 & 0.76 & 56 & 0.86 \\
\hline OSU & -37 & 0.97 & 44 & 0.91 \\
\hline UKMO & -35 & 0.92 & 51 & 0.91 \\
\hline \multicolumn{5}{|c|}{ Bias $=\mathrm{n}^{-1} \sum_{i=1}^{\mathrm{n}}\left(P_{1}-O_{i}\right)$} \\
\hline \multicolumn{5}{|c|}{ RMSE $=\left[\mathrm{n}^{-1} \sum_{i=1}^{n}\left(P_{1}-O_{i}\right)^{2}\right]^{0.5}$} \\
\hline \multicolumn{4}{|c|}{$\left[\sum_{i=1}^{\mathrm{n}}\left(P_{1}-O_{i}\right)^{2}\right.$} & \\
\hline & $=1.0-$ & $\sum_{i=1}^{\mathrm{n}}\left(\mid P_{1}\right.$ & {$\left[\overline{\left.\left|O_{2}-\bar{O}\right|\right)^{2}}\right]$} & \\
\hline \multicolumn{5}{|c|}{ where $\mathrm{n}=$ total observations (12) } \\
\hline \multicolumn{5}{|c|}{$\begin{array}{l}P_{1}=\text { model value } \\
O_{1}=\text { observed value } \\
\bar{O}=\text { mean of observed values }\end{array}$} \\
\hline
\end{tabular}

able to simulate the annual solar cycle but that they did not simulate the magnitude of incident solar radiation well. These results are similar to those found in this study, except Mearns et al. found that GCMs generally overestimated incident solar radiation in their study areas. Mearns et al. suggested that GCM-simulated cloudiness in their study areas was too low and resulted in overestimation of solar radiation. A possible explanation for the results of the present study is that GCM simulations of cloudiness for the southwestern
United States may be too high, and thus result in underestimation of incident solar radiation. Overestimation of cloudiness in the southwestern United States by the GCMs may be due, in part, to the inadequate representation of topography in the GCMs. In the GCMs the mountainous areas in the western United States are generally represented by a smoothed surface that increases in elevation from the western coast of the United States eastward to the central Rocky Mountains. This smoothing of topography may produce constant uplift of air as it moves eastward from the North Pacific Ocean into the western United States thus simulating orographic cloud formation at higherthan-observed levels over the entire southwestern United States. The GFDL GCM has the highest grid resolution of the 4 GCMs analyzed in this study and the most detailed representation of topography, and of the 4 GCMs analyzed in this study, the GFDL simulations of incident solar radiation are mlost similar to observed values.

Bias was analyzed on a seasonal basis and results indicate that the differences between GCM-simulated and observed incident solar radiation vary greatly between models and between seasons (Table 2). The OSU and UKMO simulations produce negative biases during all seasons, indicating an underestimation of incident solar radiation during all seasons. The GFDL simulations produce negative biases during winter and spring, and positive biases during summer and fall, whereas the GISS simulations produce negative biases during spring, summer, and fall, and a positive bias during winter. For the GFDL, GISS and OSU GCMs, the largest biases (positive or negative) occur during spring and summer, whereas the largest biases (positive or negative) for the UKMO GCM occur during winter and spring. For all GCMs analyzed in this study, the largest bias (positive or negative) occurs during spring.

Comparisons of changes in mean seasonal and mean annual incident solar radiation simulated by

Table 2. Mean seasonal and annual GCM-simulated values of incident solar radiation minus mean seasonal observed values, in $W \mathrm{~m}^{-2} \mathrm{~d}^{-1}$. GFDL: Geophysical Fluid Dynamics Laboratory; GISS: Goddard Institute for Space Studies; OSU: Oregon State University; UKMO: United Kingdom Meteorology Office. Mean = solar radiation network mean observed values; IOBS = interpolated mean values to model grid points from original station data; $\Delta \mathrm{SO}=$ difference between simulated values and interpolated observed values

\begin{tabular}{|c|c|c|c|c|c|c|c|c|c|}
\hline & \multirow[t]{2}{*}{ Mean } & \multicolumn{2}{|c|}{ GFDL } & \multicolumn{2}{|c|}{ GISS } & \multicolumn{2}{|c|}{ OSU } & \multicolumn{2}{|c|}{ UKMO } \\
\hline & & IOBS & $\Delta \mathrm{SO}$ & IOBS & $\Delta S O$ & IOBS & $\triangle \mathrm{SO}$ & IOBS & $\Delta \mathrm{SO}$ \\
\hline DJF & 124 & 130 & -7 & 132 & 2 & 130 & -13 & 141 & -54 \\
\hline MAM & 266 & 273 & -34 & 270 & -54 & 273 & -67 & 280 & -79 \\
\hline JJA & 316 & 319 & 19 & 309 & -12 & 317 & -43 & 318 & -1 \\
\hline SON & 186 & 192 & 8 & 189 & -7 & 191 & -23 & 198 & -6 \\
\hline Year & 220 & 229 & -4 & 225 & -18 & 228 & -37 & 234 & -35 \\
\hline
\end{tabular}


Table 3. Mean seasonal and annual GCM simulations of incident solar radiation for doubled carbon dioxide conditions minus GCM simulations for current climatic conditions, in $W \mathrm{~m}^{-2} \mathrm{~d}$ ' GFDL: Geophysical Fluid Dynamics Laboratory; GISS: Goddard Institute for Space Studies; OSU: Oregon State University; UKMO: United Kingdom Meteorology Office. Values in parentheses are \%

\begin{tabular}{|lrrrr|}
\hline Month & GFDL & GISS & OSU & UKMO \\
\hline DJF & $1(1)$ & $0(0)$ & $1(1)$ & $4(5)$ \\
MAM & $12(4)$ & $12(9)$ & $3(1)$ & $11(5)$ \\
JJA & $-6(2)$ & $-1(0)$ & $17(6)$ & $6(2)$ \\
SON & $5(3)$ & $-1(-1)$ & $3(2)$ & $3(2)$ \\
Year & $3(1)$ & $2(1)$ & $6(3)$ & $6(3)$ \\
\hline
\end{tabular}

the GCMs for the southwestern United States from $1 \times \mathrm{CO}_{2}$ to $2 \times \mathrm{CO}_{2}$ conditions mostly indicate projected increases for incident solar radiation (ranges from -1 to $17 \mathrm{~W} \mathrm{~m}^{-2} \mathrm{~d}^{-1}$ ) (Table 3 ). These projections suggest, for an annual basis, increases of from 1 to $3 \%$. The OSU and UKMO GCMs estimate increases in incident solar radiation for all seasons. The GFDL GCM simulates increases in incident solar radiation for winter, spring, and fall, but simulates a decrease for summer. The GISS GCM simulates no change in winter incident solar radiation, an increase for spring, and decreases for summer and fall. In addition, except for the GFDL GCM, the increases in mean annual incident solar radiation simulated by the $\mathrm{GCMs}$ from $1 \times \mathrm{CO}_{2}$ to $2 \times \mathrm{CO}_{2}$ conditions are much smaller than the magnitudes of the differences between GCM simulations for $1 \times \mathrm{CO}_{2}$ conditions and observed values of incident solar radiation (i.e. biases presented in Table 1).

Acknowledgements. The authors acknowledge the assistance of the National Center for Atmospheric Research (D. Joseph and R. Jenne) for access to GCM data output, under EPA Contract No. 68-W8-0113; and personnel at the Geophysical Fluid Dynamics Laboratory for access to the latest version of the GFDL model output of incident solar radiation.

Editor: V. Meentemeyer

\section{LITERATURE CITED}

Boer, G. J., Arpe, K., Blackburn, M., Deque, M., Gates, W. L., Hart, T L., le Treut, H., Roeckner, E., Sheinin, D. A., Simmonds, 1., Smith, R. N. B., Tokioka, T., Wetherald, R. T., Williamson, D. (1991). An intercomparison of the climates simulated by 14 atmospheric general circulation models. WCRP-58, WMO/TD-No. 425, WMO/ICSU World Climate Research Programme, World Meteorological Organization, Geneva

Grotch, S. L. (1988). Regional intercomparison of general circulation model predictions and historical climate data. U.S. Department of Energy, DOE/NBB-0084, Washington, DC

Grotch, S. L., MacCracken, M. C (1991). The use of general circulation models to predict regional climatic change. J. Clim. 4: 286-303

Hansen, J., Russell, G., Rind, D., Stone, P., Lacis, A., Lebedeff, S., Ruedy, R., Travis, L. (1983). Efficient three-dimensional global models for cimate studies - models I and II. Mon. Weather Rev. 111: 609--662

Kalkstein, L. S. (ed.) (1991). Global comparisons of selected GCM control runs and observed climate data. U.S. Environmental Protection Agency, Office of Policy, Planning, and Evaluation, Climate Change Division (Subcontract to ICF, Inc.), EPA Contract No. 68-W8-0113, Washington, $\mathrm{DC}$

Knapp, C. L., Stoffel, G. L., Whitaker, S. D. (1990). Insolation data manual and direct normal solar radiation data manual. Solar Energy Information Data Bank, Golden, CO

Manabe, S., Broccoli, A. J. (1990). Mountains and arid climates of middle latitudes. Science 247: 192-195

Mearns, L. O., Schneider, S. H., Thompson, S. L., Danicl, L. R. (1989). Analysis of climate variability in general circulation models: comparisons with observations and changes in variability in $2 \times \mathrm{CO}_{2}$ experiments. In: Smith, J. B., Tirpak, D. A. (eds.) The potentral effects of global climate change on the United States: Appendix I - Variability. U.S. Environmental Protection Agency, Office of Policy, Planning, and Evaluation, Washington, DC, p. 1-59

Schlesinger, M. E., Gates, W. L. (1980). The January and July performance of the OSU two-level atmospheric general circulation model. J. Atmos. Sci. 37: 1914-1943

Willmott, C. J. (1981). On the validation of models. Phys. Geogr. 2: $184-194$

Willmott, C. J., Rowe, C. M., Philpot, W. D. (1985). Small scale climate maps: a sensitivity analysis of some common assumptions associated with grid point interpolation and contouring. Am. Cartogr. 12:5-16

Willmott, C. J., Vernon, M. T. (1980). Solar climates of the conterminous United States: a preliminary investigation. Sol. Energy 24: 295-303

Manuscript first received: March 1, 1993

Revised version accepted: June 23, 1993 